\title{
Rheological properties of conductive polymer composite (CPC) filled with double percolated network of carbon nanoparticles and boron nitride powder
}

\author{
Guillaume Droval, ${ }^{1}$ Jean-François Feller, ${ }^{2 *}$ Patrick Salagnac, ${ }^{2}$ Patrick Glouannec ${ }^{2}$ \\ ${ }^{1}$ CEMES-CNRS, Université de Toulouse, 29 rue Jeanne Marvig, BP 94347, 31055 \\ Toulouse Cedex 4, France. \\ $2^{*}$ LIMATB, Université de Bretagne Sud, centre de recherche, rue Saint-Maudé, BP \\ 92116, 56321 Lorient, France ; tel.: +33 2978745 84; fax: +33 2978745 88, e- \\ mail: Jean-Francois.Feller@univ-ubs.fr
}

(Received: 20 August, 2008; published: 23 February, 2009)

\begin{abstract}
In this study, double percolated network of carbon nanoparticles and ceramics powder is used to uncouple electrical and thermal conductivity of polymer composite. The influence of ceramic powders on morphological properties of a biphasic conductive polymer composite (CPC) is investigated by means of rheological measurements. The biphasic materials studied are blends of a thermally conductive polymer phase (syndiotactic poly(styrene) (sPS) filled with boron nitride $(\mathrm{BN})$ ) with an electrically conductive polymer phase (high-density poly(ethylene) (hdPE) filled with nano-structured carbon black (NCB)) into a cocontinuous structure. The elastic modulus (with viscous modulus) was found to be the most sensitive rheological property to accurately detect the co-continuous morphology in our system. It was found to be at $40 \% \mathrm{v} / \mathrm{v}$ of hdPE-NCB, which can be interpreted as the phase inversion.
\end{abstract}

\section{Introduction}

Conducting polymer composites (CPC) result from a blending between insulating polymer and electrically conducting fillers (carbon black, metals particles) [1, 2]. Their formulation can be adapted in order to satisfy different characteristics of electrical properties (resistivity, percolation threshold) with temperature [3], pressure [4], or solvent [5] solicitations. This gives CPC a sensitivity towards their environment; these very versatile materials can be used for several applications such as self-regulated heating $[6,7]$, electro-magnetic shielding $[8,9]$, or vapour sensing $[5,10]$.

Biphasic CPCs can give original properties as long as thermodynamic stability is well controlled [11, 12]. A good understanding of the numerous influencing factors is necessary to obtain desired features. One of the most important factors is the level of structure (or dispersion) of conductive particles within the matrix [13, 14], which depends on: processing conditions (temperature, shear rate, viscosity, and particles orientation) [15, 16], formulation (fillers nature, molar weight, and crystallinity of polymer), solubility parameters, particles/particles and particles/macromolecules interactions, volume exclusion domain, micro phase segregation and self aggregations [17, 18, 19].

For basic applications, on the purpose to get cheap and easy processing CPC, it is useful to reduce the percolation threshold, i.e., the quantity of filler beyond which the 
CPC becomes electrically conductive. This target can be achieved by the use of cocontinuous biphasic polymers (immiscible blend) where the fillers are dispersed in only one phase [20].

For self-regulated heating application [6], despite the numerous advantages brought by biphasic CPC, their low thermal conductivity, resulting from the polymers matrix (which are good thermal insulators), is a major drawback to reach high power density levels [21]. A solution to this problem is to improve the thermal conductivity by adding thermally conductive fillers in the CPC [22]. However, this addition may also have consequences on electrical and rheological properties.

The high density polyethylene is used for its excellent capacity of self regulation [23, 24] as electrically conductive phase. Effectively, this polymer is known for its high thermal expansion that disconnects the conducting path during the PTC (Positive Temperature Coefficient) transition.

The syndiotactic poly(styrene) is known for its chemical and thermal stability and is used as thermally conductive phase. Moreover, this polymer does not significantly alter the amplitude of the PTC effect and reduce the NTC effect (Negative Temperature Coefficient), which is a non desirable feature because of decrease of electrical resistivity. This phase being the thermal conductive phase, it must be the majority. Moreover the sPS phase also provides to the biphasic CPC a mechanical stiffness at high temperature. Thus in this study, the coupling of the two phases is investigated by means of rheological properties to evaluate the beginning of continuous region of the electrical phase corresponding to a maximum heat dissipation and sufficient electrical conduction in the biphasic CPC. The electrical properties were studied in a previous work [25].

\section{Results and discussion}

In the first part, we consider each phase (electrically and thermally conductive phase) separately at $280{ }^{\circ} \mathrm{C}$, the processing temperature of the biphasic polymer blend. During processing, under shear effect, stresses applied to the blend tend to deform, then stretched up to breaking of polymer dispersed inclusions. This dispersive effect is governed by the viscosity ratio and/or elasticity ratio of each phase.

\section{Monophasic blend study}

\section{-Electrical conductive phase hdPE-NCB}

\section{Shear rate effect on the viscosity}

In Fig. 1., all experimental data exhibit a Newtonian flow behavior appearing at low shear rate followed by a shear shinning flow behavior beyond the critical shear rate $\dot{\gamma}_{c}$. For the purpose of accurately determining the influence of carbon black, the coefficients are given in Tab. 1 for the three models: power law (Eq. 3), Cross model (Eq. 4 and Carreau model (Eq. 5). For polymer (shear thinning flow), the pseudoplastic index " $n$ " is included between "0" (very shear shinning flow behavior) and "1" (Newtonian flow). We can see in the table that " $n$ " decreases from "0.3" for pristine hdPE to "0" for hdPE filled over $16.5 \%$ of NCB. As the carbon black content increase from 0 to $23 \%(\mathrm{v} / \mathrm{v})$, the viscosity at Newtonian flow " $\eta_{0}$ " rises from $4 \times 10^{4}$ up to $10^{7}$ Pa.s and the critical shear rate " $\dot{\gamma}_{c}$ " decreases from 0.067 to $0.001 \mathrm{~s}^{-1}$. This 
rise of " $\eta_{0}$ " while " $\dot{\gamma}_{c}$ " decreases tend to make the Newtonian plateau disappear as already noticed with blend of poly(ethylene-co-ethyl acrylate)-carbon black (EEANCB) [26].

For hdPE composites with less than $16.5 \%(\mathrm{v} / \mathrm{v})$ of carbon black, measurements at a shear rate higher than $1 \mathrm{~s}^{-1}$ came with an increase of the normal force $\mathrm{N}_{1}$ (Eq. 1). N1, the first difference of normal stress, is a parameter linked with the elasticity of the melt material. About plate/plate rheometer, $N_{1}$ is measured through the force $F$ applied by the sample to the top plate due to shear rate undergone in the perpendicular plane.

$N_{1}=\sigma_{x x}-\sigma_{y y}=\frac{2 F}{\pi R^{2}}$

The force $\mathrm{F}$ is given by the elasticity of macromolecular chains that orient themselves according to the current line, under the effect of shear rate. This phenomenon put into evidence by Weissenberg [27] is specific to polymers. The softening of the elastic effect for high NCB content composites can be explained by the very high dispersive viscous component of the melt material. The change of the normal force $\mathrm{N}_{1}$ during measurement is presented in Fig. 2.

Tab. 1. Models parameters for fitting with hdPE-NCB experimental curves.

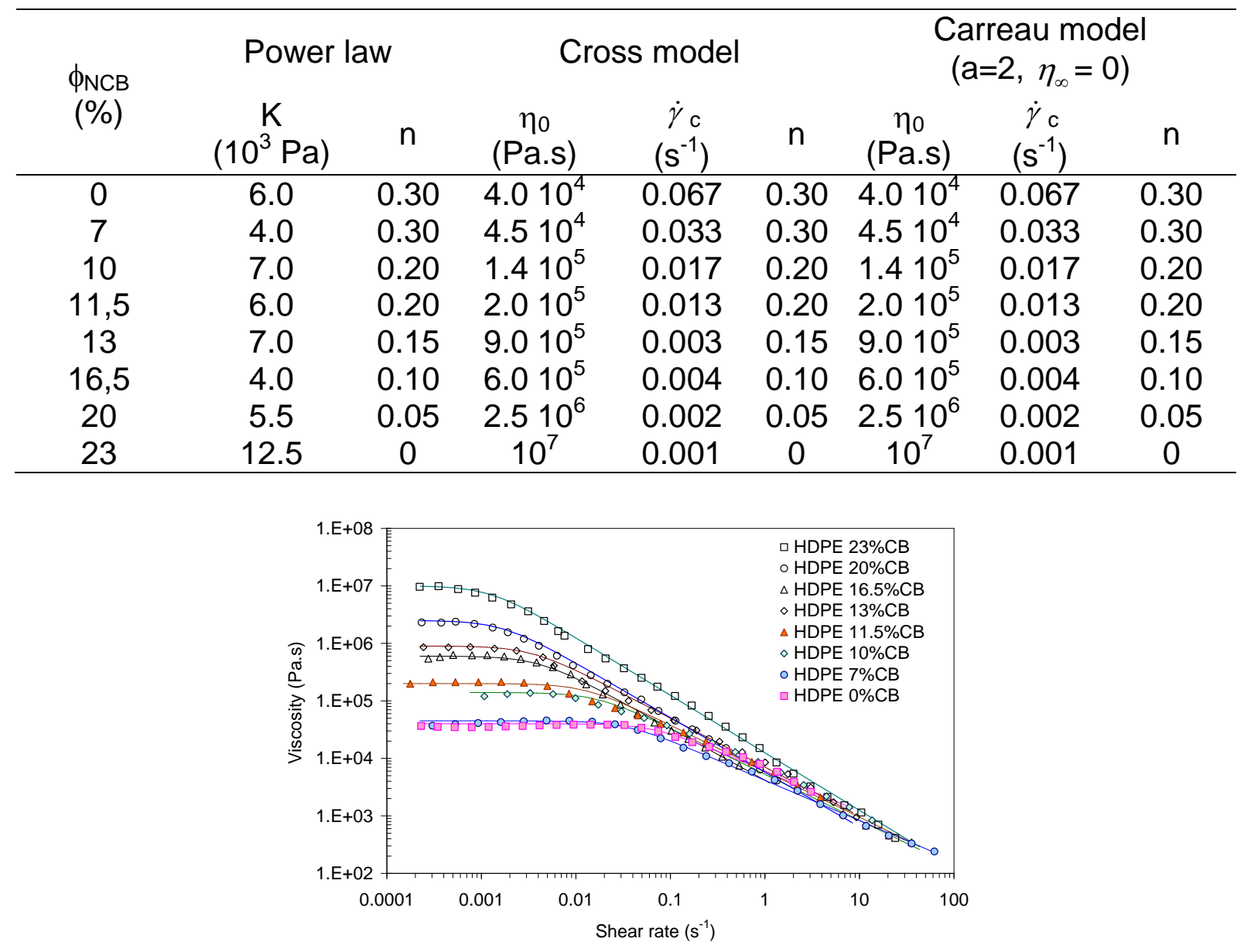

Fig. 1. Viscosity of hdPE with the Carreau model (plain line) as a function of shear rate at $280^{\circ} \mathrm{C}$. 


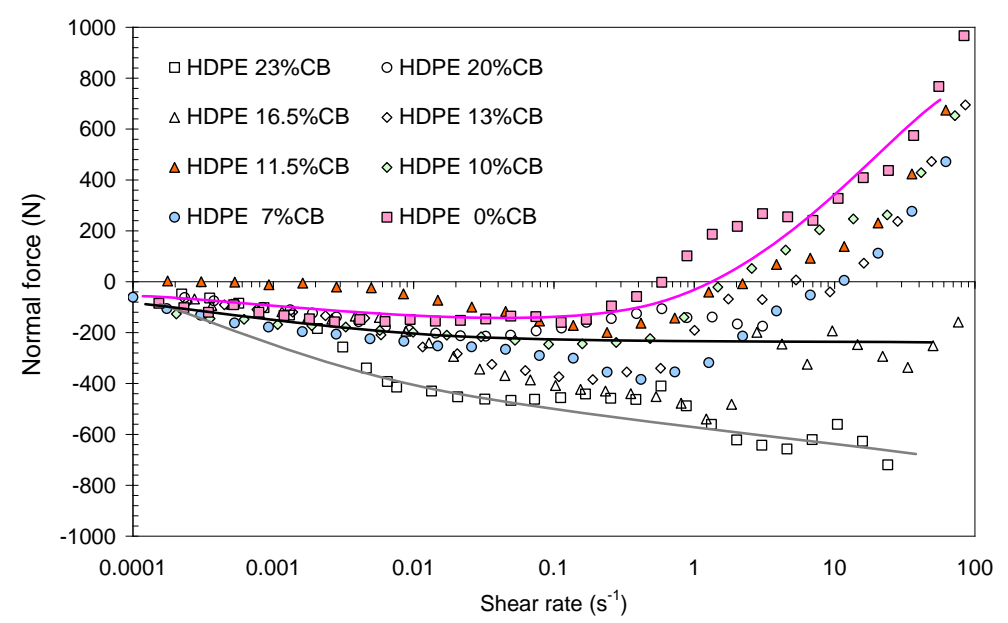

Fig. 2. Normal force during measurements of hdPE viscosity as a function of the shear rate.

\section{-Carbon black effect on the hdPE viscosity}

In Fig. 3, we can see that the Maron \& Pierce models (plain lines) can be applied successfully to the experimental data for values of shear rate lower than $0.1 \mathrm{~s}^{-1}$.

The values of $\phi_{\mathrm{m}}$, maximum volume fraction, from Maron \& Pierce models given in Tab. 2 shows that faster the shear rate, the higher $\phi_{m}$ and thus the shape factor of aggregates is small. The low values of $\phi_{\mathrm{m}}$ obtained with slow shear rates points out that the conducting network is formed from particles associated in very well structured aggregates (high shape factor). With a stress sufficiently high (above a shear rate of $0.1 \mathrm{~s}^{-1}$ for instance), NCB aggregates are destructured up to a more spherical shape [26]. Moreover, in Fig. 3, we can see that at slow shear rate, for NCB content higher than $18 \%(\mathrm{v} / \mathrm{v})$, the experimental ratio $\| \eta / \eta_{\mathrm{m}}$ 》 is below the model prediction. This could be explained by a decrease of interactions between aggregates and macromolecules due to presence of "voids" between particles.

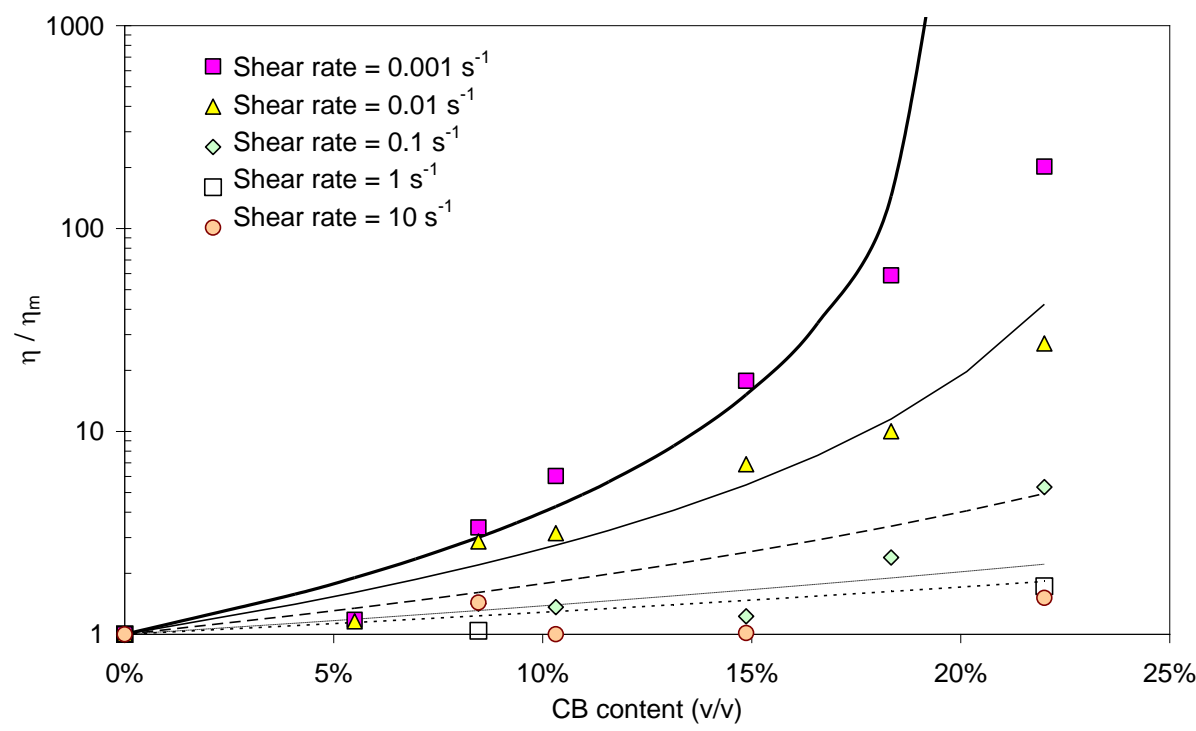

Fig. 3. Relative viscosity of hdPE-NCB as a function of NCB content (curve: Maron \& Pierce models, markers: experimental data). 
In the processing conditions (two contra-rotative screws at $20 \mathrm{rpm}$ ), the different shear rates are from 2 to $55 \mathrm{~s}^{-1}$. This gives a very high $\phi_{\mathrm{m}}$ (between 67 and 85\%) which is however coherent with theory for spherical particles (\# 64\%) [28, 22].

Tab. 2. Comparison between $\phi_{m}=f(L / D)$ and $\phi_{m}=g$ (shear rate).

\begin{tabular}{cccc}
\hline $\mathrm{L} / \mathrm{D}$ & $\phi_{\mathrm{m}}[29]$ & $\dot{\gamma}\left(\mathrm{s}^{-1}\right)$ & $\phi_{\mathrm{m}}(\exp )$. \\
\hline 30 & 0.173 & 0.001 & 0.20 \\
16 & 0.303 & 0.01 & 0.26 \\
8 & 0.476 & 0.1 & 0.40 \\
& & 1 & 0.67 \\
& & 10 & 0.85 \\
\hline
\end{tabular}

-Thermal conductive phase

Shear rate effect on the viscosity

In a previous work [22], we have shown that boron nitride (BN) was a very efficient filler to increase the sPS thermal conductivity. However, considering the low viscosity of SPS at $280^{\circ} \mathrm{C}$, the maximum level of viscosity reached with these composites is barely higher than the one of pristine hdPE at the same temperature.

The study of the thermal conductive phase was performed with samples prepared by melt blending of SPS matrix with fillers in a mini extruder with two conical screws, MINILAB from HAAKE. Compounds were blended for 15 min at $280{ }^{\circ} \mathrm{C}$ with a mixing speed of $100 \mathrm{rd} \cdot \mathrm{min}^{-1}$ and afterwards injected in a small mould under $4 \mathrm{MPa}$. Different composites formulations were obtained with filler content from 0 to $30 \%$ $(\mathrm{v} / \mathrm{v})$.

The flow behavior of sPS-BN composites at $280{ }^{\circ} \mathrm{C}$ are presented in the Fig. 4. The experimental data are fitted with the models (power law, Cross and Carreau-Yasuda) and their coefficients are given in Tab. 3.

Tab. 3. Models parameters for sPS-BN.

\begin{tabular}{cccccccccc}
\hline \multirow{3}{*}{$\begin{array}{c}\text { PBN } \\
\text { Power law }\end{array}$} & \multicolumn{3}{c}{ Cross } & \multicolumn{4}{c}{ Carreau - Yasuda, $\eta_{\infty}=0$} \\
$(\%)$ & $(\mathrm{Pa})$ & $\mathrm{n}$ & $\begin{array}{c}\eta_{0} \\
(\mathrm{~Pa}) \mathrm{s})\end{array}$ & $\begin{array}{c}\dot{\gamma}_{\mathrm{c}} \\
\left(\mathrm{s}^{-1}\right)\end{array}$ & $\mathrm{n}$ & $\eta_{0}$ & $\dot{\gamma}_{\mathrm{c}}$ & $\mathrm{a}$ & $\mathrm{n}$ \\
\hline 0 & 17 & 0.9 & 19 & 0.333 & 0.9 & 19 & 0.333 & 2.0 & 0.9 \\
9 & 85 & 0.85 & 160 & 0.017 & 0.85 & 160 & 0.017 & 2.0 & 0.85 \\
14 & 200 & 0.6 & 1150 & 0.013 & 0.6 & 1150 & 0.013 & 1.5 & 0.6 \\
19 & 210 & 0.3 & $1.110^{4}$ & 0.004 & 0.3 & $1.110^{4}$ & 0.004 & 1.1 & 0.3 \\
27 & 600 & 0.1 & $910^{4}$ & 0.004 & 0.1 & $910^{4}$ & 0.004 & 0.8 & 0.1 \\
\hline
\end{tabular}

In the range from 0 to $27 \%$ of $B N$, the viscosity at Newtonian flow is from 19 up to $910^{4} \mathrm{~Pa}$.s. In the same range, the pseudoplastic index decreases from 0.9 to 0.1 and the parameter "a" of Carreau-Yasuda model goes down from 2 to 0.8 .

The very high pseudoplastic index of the pristine SPS (close to 1) indicates a strong Newtonian behavior which tends to prove a weak cooperative behavior of macromolecular chains due to a narrow distribution of molecular weight $\left(I_{p}\right)$ and/or a 
low degree of polymerization $\mathrm{DP}_{\mathrm{n}}$. The addition of $\mathrm{BN}$ particles strongly increases the pseudoplastic behavior and viscosity (at slow shear rate).

Unlike with hdPE-NCB systems, the normal force $\mathrm{N}_{1}$ with sPS-BN systems is close to zero (Fig. 5). Therefore, there is no Weissenberg effect. This means that elasticity of sPS blends is very poor, which is coherent with the Newtonian behavior of sPS.

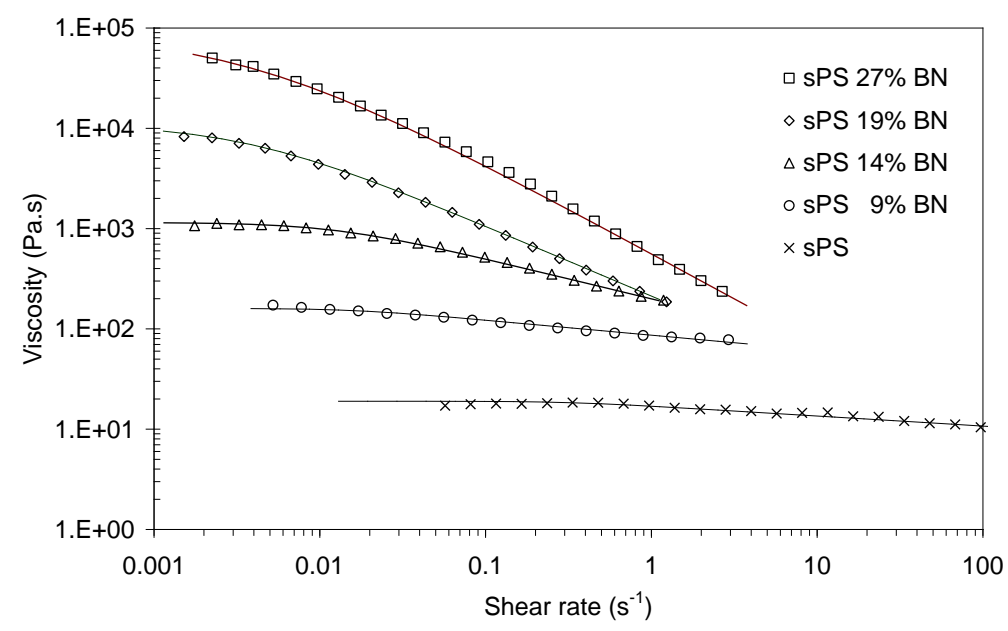

Fig. 4. SPS-BN viscosity as a function of shear rate.

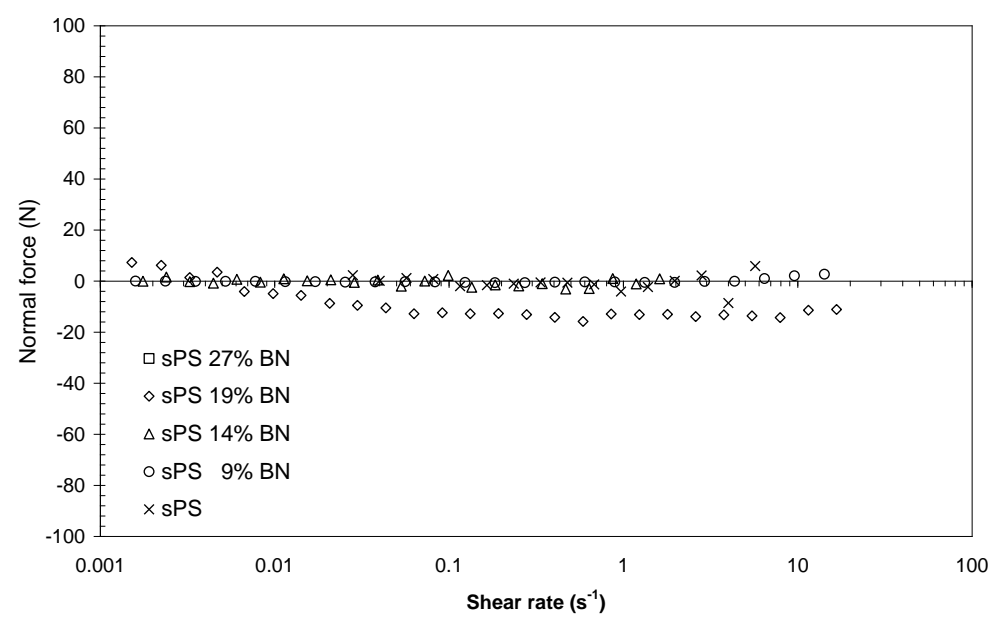

Fig. 5. Normal force during viscosity measurement (PS-BN).

\section{-Boron nitride effect on SPS viscosity}

In Fig. 6, the change of viscosity as function of BN content is a lot more progressive and linear than hdPE-NCB system and is also a lot more important for low volume fraction of particles. That is why the Maron \& Pierce model is not suitable for describing this change of viscosity whereas the Dean-Mo equation [30] has been successfully tested with ceramics particles. The calculation slope "a" is presented in Fig. 7. For shear rates high enough (above $1 \mathrm{~s}^{-1}$, the shear rate during processing is estimated about $100 \mathrm{~s}^{-1}$ ), the maximum volume fraction evaluated through the Eq. (8) gives a $\phi_{m}$ value of about $39 \%$, which is coherent with $40 \%$, the $\phi_{m}$ determined in a previous work [22] by the measurement of the apparent density. Furthermore, a value of $55 \%$ is found with the measure of apparent density of aluminum oxide [22]. 
This value is surprisingly close to the value $54.2 \%$ given for a similar system "aluminum oxide/glycerin" presented in the Dean-Mo paper [30].

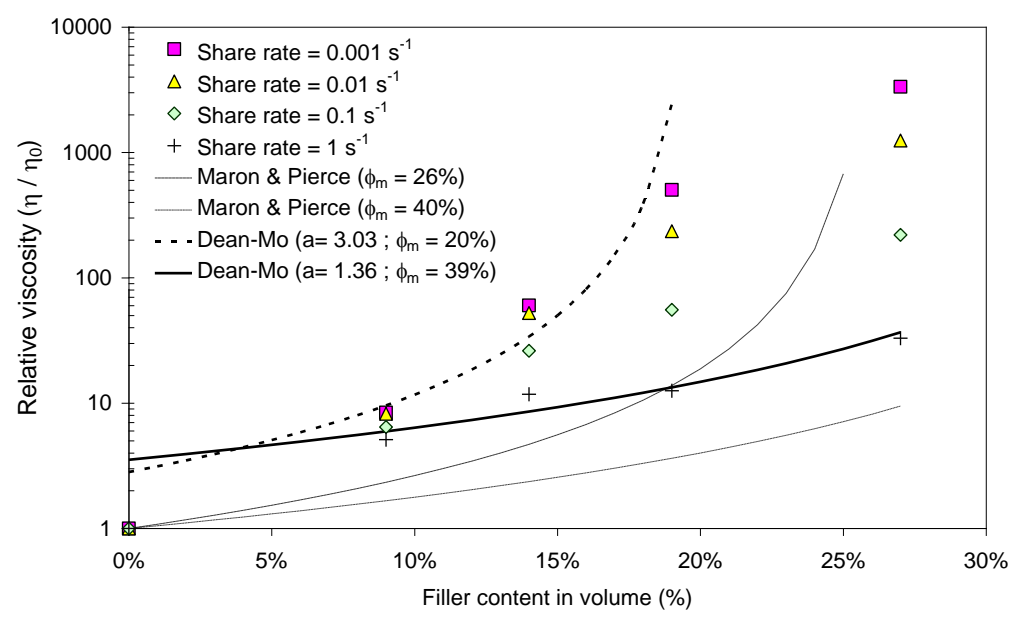

Fig. 6. The change of viscosity as function of BN content; comparison of Maron \& Pierce and Dean-Mo models.

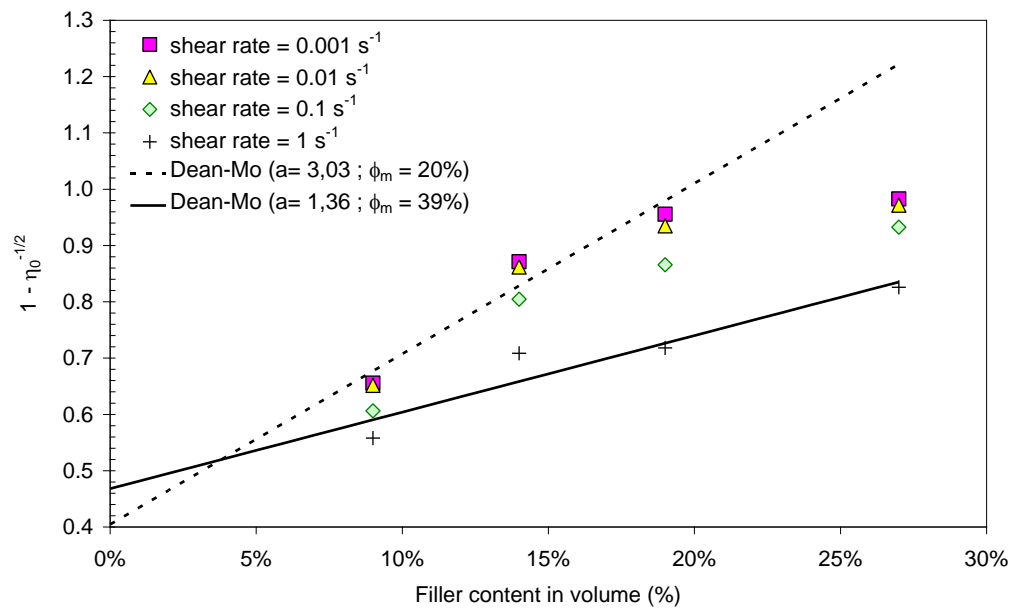

Fig. 7. Determination of parameters a and $\phi_{m}$ (Dean-Mo model [30]).

-Influence of solicitation time

In this part, the change of viscosity with time is studied because the mixing times of monophasic during the melt processing are not equivalent (15 min in MiniLab and about 2 min in the twin screws Brabender).

The change of complex viscosity as a function of time is presented in Fig. 8. The tests are carried out on samples of hdPE-13\%NCB (v/v) and pristine sPS. During experiments, the frequency applied is $1 \mathrm{~Hz}$ with a strain of $0.5 \%$ at $280^{\circ} \mathrm{C}$. Theses measures demonstrate that polymers used undergo transformations of contrary nature. For instance, in $30 \mathrm{~min}$, the hdPE-13\%NCB viscosity is multiplied by four. This increase certainly results from a cross-linkage phenomenon (due to thermolysis) and is followed by a reaction of chains between themselves or with fillers. This is not surprising since the hdPE matrix has been measured $140{ }^{\circ} \mathrm{C}$ above its melt temperature. On the other side, the pristine sPS diminishes with time. This reveals a 
phenomenon of chain scission. Even if this decrease is not as important as the one with hdPE-13\%NCB, considering the processing shear rate $\left(>100 \mathrm{~s}^{-1}\right.$ instead of $<55 \mathrm{~s}^{-1}$ with Brabender) and time (15 min against $2 \mathrm{~min}$ ), the sPS is the material that has undergone the most important transformation except for the duration of rheological measurements.

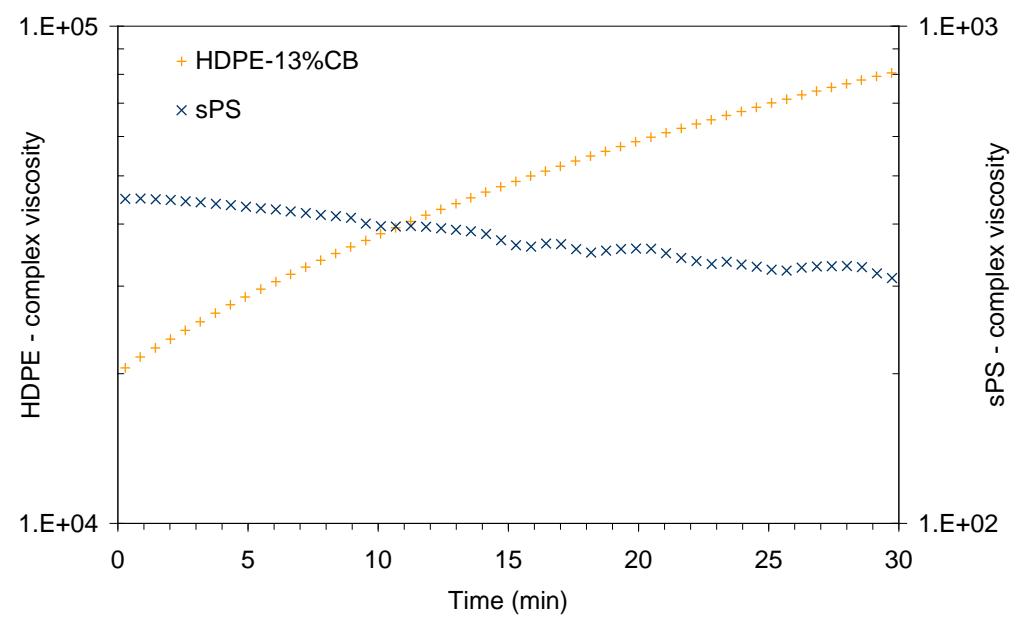

Fig. 8. Dynamic viscosity of hdPE-NCB and sPS as a function of time at $280^{\circ} \mathrm{C}$.

\section{Study of biphasic blends}

The morphology obtained from immiscible blends of two polymers are rather various: nodule, lamella, co-continuous phases or double gyroïdes [31] and depend on the ratio of polymers, the shear rate, viscosity ratio or surface tensions.

The study of rheological properties give information both about the change of morphology occurring in the blend and how to optimize the processing conditions with the purpose to find a good reproducibility of final properties.

Four biphasic blends of hdPE-23\%NCB with sPS have been processed in the Brabender extruder at $20 \mathrm{rd} \cdot \mathrm{min}^{-1}$ and at $280^{\circ} \mathrm{C}$ to study the rheological properties (Tab. 4). The weight has been measured by TGA (Thermogravimetric analysis) and the volume fraction has been calculated from the density measurement with a pycnometer.

Tab. 4. Formulation of blends hdPE-23\%NCB/sPS.

\begin{tabular}{cccc}
\hline $\begin{array}{c}\text { hdPE-23\% } \\
\text { NCB/sPS }\end{array}$ & density $\left(\mathrm{kg} \cdot \mathrm{m}^{-3}\right)$ & $\phi_{\mathrm{SPS}}$ & $\phi_{\mathrm{NCB}}$ \\
\hline $20 / 80$ & 1064 & $85 \%$ & $3.4 \%$ \\
$40 / 60$ & 1085 & $58 \%$ & $9.6 \%$ \\
$60 / 40$ & 1097 & $43 \%$ & $13.0 \%$ \\
$80 / 20$ & 1118 & $17 \%$ & $19.0 \%$ \\
\hline
\end{tabular}

-Shear rate effect on the viscosity

The change of viscosity of biphasic system is presented in Fig. 9. These curves have been fitted with the three previous models (power law, Cross and Carreau-Yasuda model). The model coefficients are given in Table 5 . We can see that the viscosity 
quickly rise with a small amount of hdPE-23\%NCB (up to $40 \%$ of hdPE-23\%NCB). The pseudoplastic index follows almost the same change with a fast decrease from 0.85 up to 0.2 for $40 \%$ of hdPE-23\%NCB.

Unlike the previous study of sPS (compounds elaborated in Minilab), the sPS viscosity processed in Brabender is about $290 \mathrm{~Pa}$.s instead of $19 \mathrm{~Pa}$.s. The knowledge of SPS behavior with respect to time permits consideration of a decrease of viscosity in Minilab due to a drop of molecular weight. In fact, the empirical Bueche law [32] (Eq. (2)) shows that the change of molecular weight has an effect upon the viscosity by a power " 3.4 ", where $\mathrm{K}$ is a constant:

$\eta=K\left[\bar{M}_{w}\right]^{3.4}$

Tab. 5. Models coefficients for biphasic blends hdPE-23\% NCB with s/PS at $280^{\circ} \mathrm{C}$.

\begin{tabular}{ccccccccc}
\hline $\begin{array}{c}\text { (hdPE- } \\
\text { 23\%NCB }) / \mathrm{sPS} \\
(\mathrm{v} / \mathrm{v})\end{array}$ & \multicolumn{2}{c}{ Power law } & \multicolumn{3}{c}{ Cross model } & \multicolumn{4}{c}{$\begin{array}{c}\text { Carreau-Yasuda model, } \\
\left(\mathrm{a}=2 \eta_{\infty}=0\right)\end{array}$} \\
& $\begin{array}{c}\mathrm{K} \\
\left(10^{3} \mathrm{~Pa}\right)\end{array}$ & $\mathrm{n}$ & $\begin{array}{c}\eta_{0} \\
(\mathrm{~Pa} . \mathrm{s})\end{array}$ & $\begin{array}{c}\dot{\gamma}_{\mathrm{c}} \\
\left(10^{-3} \mathrm{~s}^{-1}\right)\end{array}$ & $\mathrm{n}$ & $\begin{array}{c}\eta_{0} \\
(\mathrm{~Pa} . \mathrm{s})\end{array}$ & $\begin{array}{c}\dot{\gamma}_{c} \\
\left(10^{-3} \mathrm{~s}^{-1}\right)\end{array}$ & $\mathrm{n}$ \\
\hline $0 / 100$ & 0.27 & 0.85 & 290 & 1000 & 0.85 & 290 & 1000 & 0.85 \\
$15 / 85$ & 1.1 & 0.6 & $1.010^{4}$ & 4.0 & 0.6 & $1.010^{4}$ & 4.0 & 0.6 \\
$42 / 58$ & 2.3 & 0.2 & $3.510^{5}$ & 2.0 & 0.2 & $3.510^{5}$ & 2.0 & 0.2 \\
$57 / 43$ & 6.0 & 0.2 & $1.110^{7}$ & 0.1 & 0.2 & $1.110^{7}$ & 0.1 & 0.2 \\
$83 / 17$ & 10.0 & 0.1 & $8.010^{6}$ & 0.5 & 0.1 & $8.010^{6}$ & 0.5 & 0.1 \\
$100 / 0$ & 12.5 & 0 & $1.010^{7}$ & 1.3 & 0 & $1.010^{7}$ & 1.3 & 0 \\
\hline
\end{tabular}

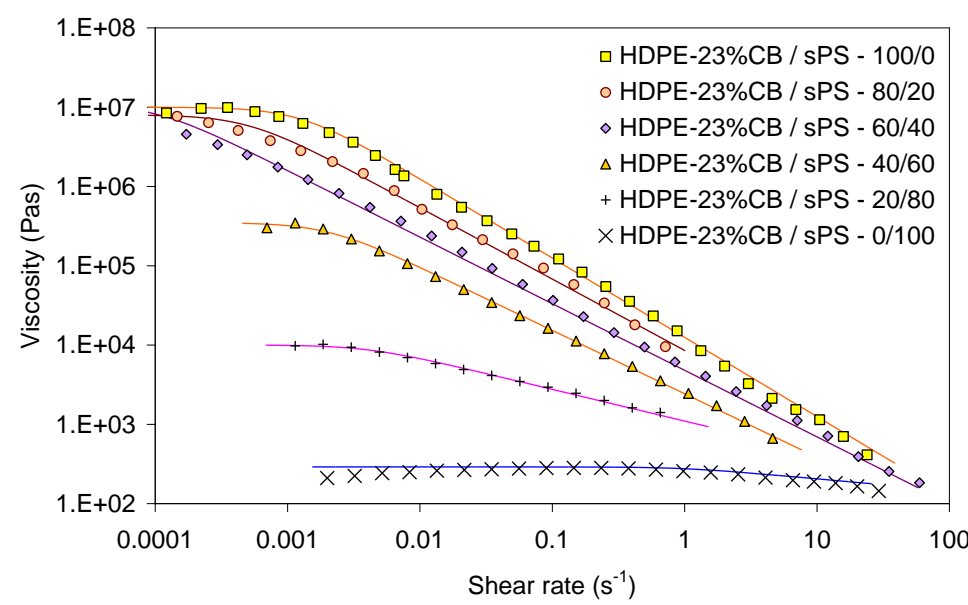

Fig. 9. Viscosity of biphasic blends hdPE-23\%NCB/sPS at $280^{\circ} \mathrm{C}$.

-Effect of filler content on the viscosity

The curves in Fig. 10 put into evidence what has been proposed in the previous paragraph. The plain lines in the figure are only drawn to guide eyes and do not represent any model. In this way, the viscosity change as a function of NCB content is emphasized and this represents roughly a logarithmic behavior that tends towards an horizontal asymptote for $40 \%$ of hdPE- $23 \% \mathrm{NCB}$ phase (equivalent to $9 \%$ of NCB). 


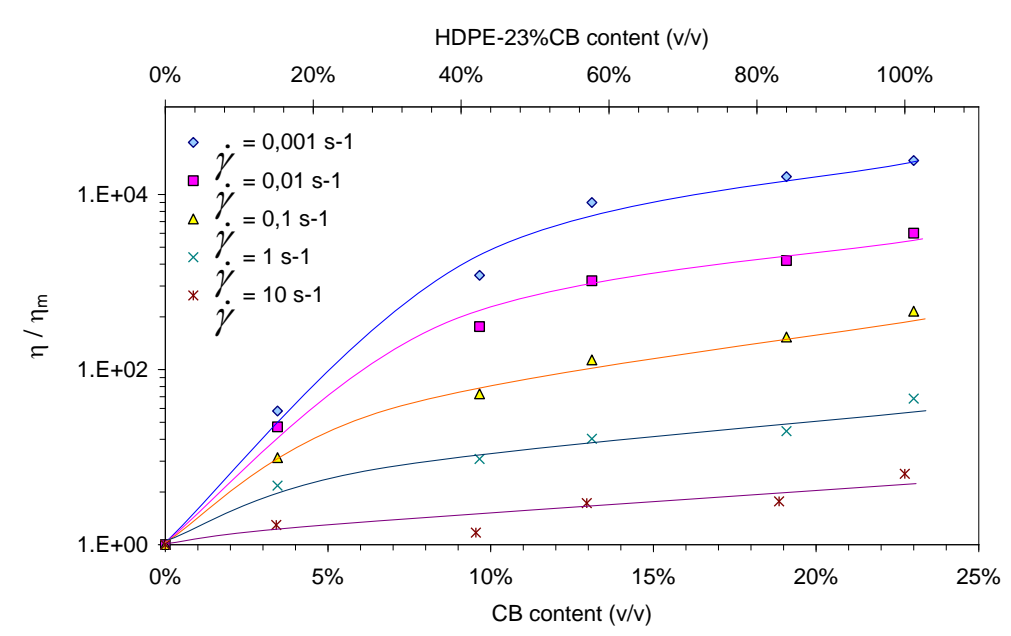

Fig. 10. Biphasic viscosity as a function of hdPE-23\%NCB or NCB content at $280^{\circ} \mathrm{C}$.

\section{-Complex modulus change}

Prior to frequency sweep analysis, strain sweep experiments have been performed at a constant frequency of $1 \mathrm{~Hz}$ (corresponding to middle frequency range) to determine the linear viscoelastic region. The results, presented in Fig. 11, show that from $40 \%$ of hdPE-23\% NCB in SPS, the linearity region is drastically reduced. In order to carry out frequency sweep experiments in correct conditions, the strain amplitude solicitation must be inferior to $0.5 \%$.

Tab. 6. Cross-over and slope of the storage G' and loss G" modulus of the biphasic blends.

\begin{tabular}{cccc}
\hline $\begin{array}{c}\text { hdPE-23\% NCB/sPS } \\
\text { blends }\end{array}$ & $\begin{array}{c}\text { cross-over } \\
\text { frequency }(\mathrm{Hz})\end{array}$ & $\begin{array}{c}\text { G' } \\
\text { slope }\end{array}$ & $\begin{array}{c}\text { G' } \\
\text { slope }\end{array}$ \\
\hline $100 / 0$ & - & 0.05 & 0.25 \\
$80 / 20$ & - & 0.05 & 0.25 \\
$60 / 40$ & - & 0.20 & 0.30 \\
$40 / 60$ & $1-15$ & 0.40 & 0.40 \\
$20 / 80$ & $32-57$ & 0.83 & 0.65 \\
$0 / 100$ & 57 & 1.3 & 0.83 \\
\hline
\end{tabular}

The curves in Fig. 12 present the change of loss G" and storage G' modulus as a function of frequency for each phase of the biphasic. The SPS phase has a classical behavior with a higher loss modulus for the most of frequency range studied, which is in accordance with literature [33]. After the "cross over", $60 \mathrm{~Hz}$, the storage modulus becomes more important. This behavior is characteristic of a macromolecular flow weakly cooperative.

On the other hand, the hdPE-23\% NCB behavior is totally different and represents an interconnected network of macromolecules relatively stable with change of frequency. The presence of plateau at low frequency is not surprising because the experiments are performed from high to low frequencies and last about 10 min hence an increase of modulus with time (see in Fig. 8).

The change of modulus (storage and loss) is presented in Fig. 13. We can notice that the storage modulus is higher than the loss modulus for the blends with more than 
$40 \%$ of hdPE-23\% NCB. Afterwards, the cross-over does not occur at a singular frequency but is spread over a large frequency range; the data is given in Tab. 6 .

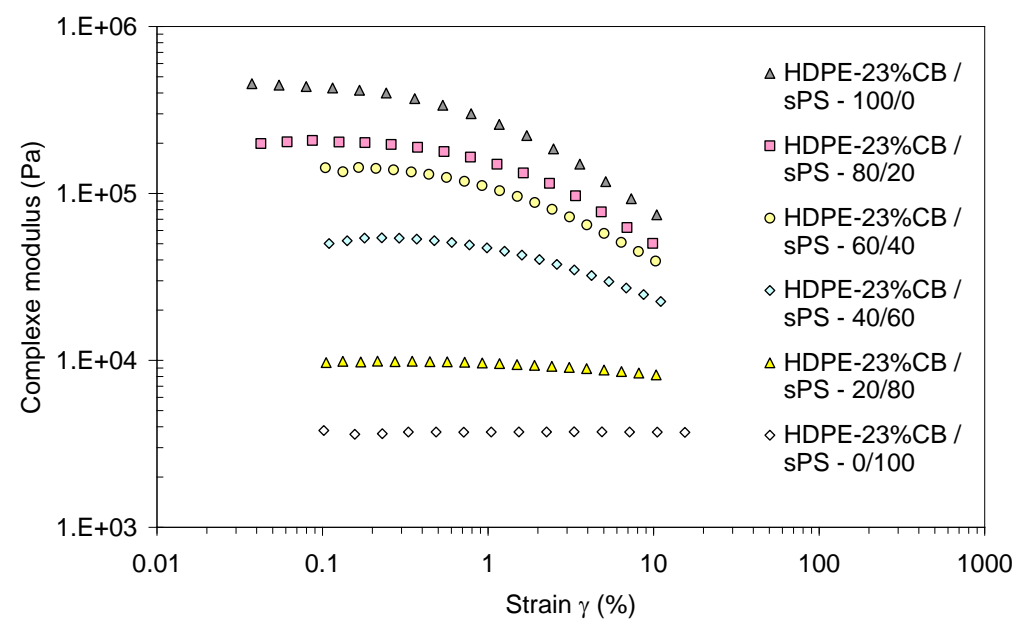

Fig. 11. Complex modulus of biphasic blends (hdPE $23 \%$ NCB)/sPS as a function of strain at $280^{\circ} \mathrm{C}$.

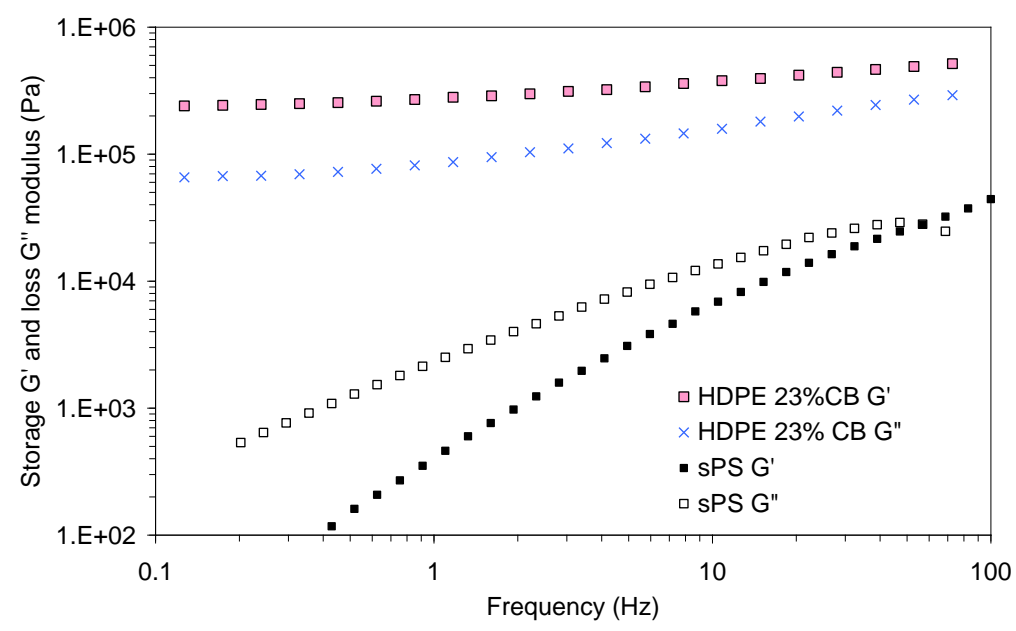

Fig. 12. Storage and loss modulus of hdPE-23\%NCB and sPS as a function of frequency at $280^{\circ} \mathrm{C}$.

With the purpose to put into evidence the quantity of hdPE-23\% NCB necessary to get an overlapping of the modulus, their slope, measured in the "linear" region between 1 and $10 \mathrm{hz}$, are given in Tab. 6 and plotted in Fig. 14. These plots show a crossing at $38 \%$ of hdPE-23\%NCB. We can also point out the change of loss modulus (from 0.83 to 0.25 ) to be more progressive compared to the storage one (from 1.3 to 0.05). The modulus slope seems to be a relevant parameter to follow the mechanical percolation (beginning of co-continuity) of the system hdPE-23\% NCB / sPS.

The notion of mechanical percolation naturally leads to a particular interest in morphology changes in the CPC in accordance with composition and mixing conditions. In fact, morphology has a direct consequence onto mechanical properties but to electrical resistivity as well. When the quantity of hdPE-NCB is low, this phase is dispersed as droplets of high viscosity slightly stretched under shear rate effect. 
With an increase of hdPE-NCB, the droplets are merging, that is coalescence, until they form long ellipsoids, and themselves constitute a continuous phase over $38 \%$ of hdPE-NCB. Afterwards, viscosity of the system does not change any more whatever the shear rate since hdPE-NCB has become majority.
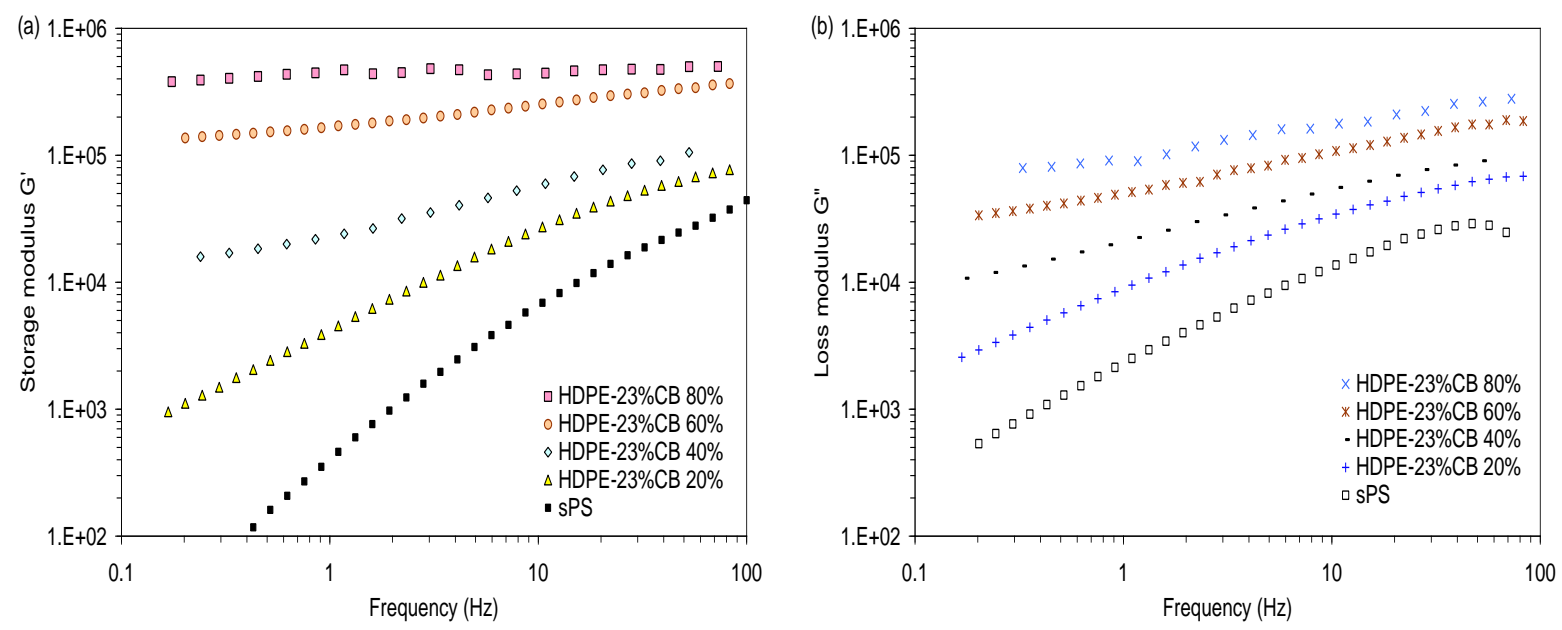

Fig. 13. Storage (a) and loss (b) modulus of biphasic blends hdPE-23\% NCB/sPS as a function of frequency at $280^{\circ} \mathrm{C}$.

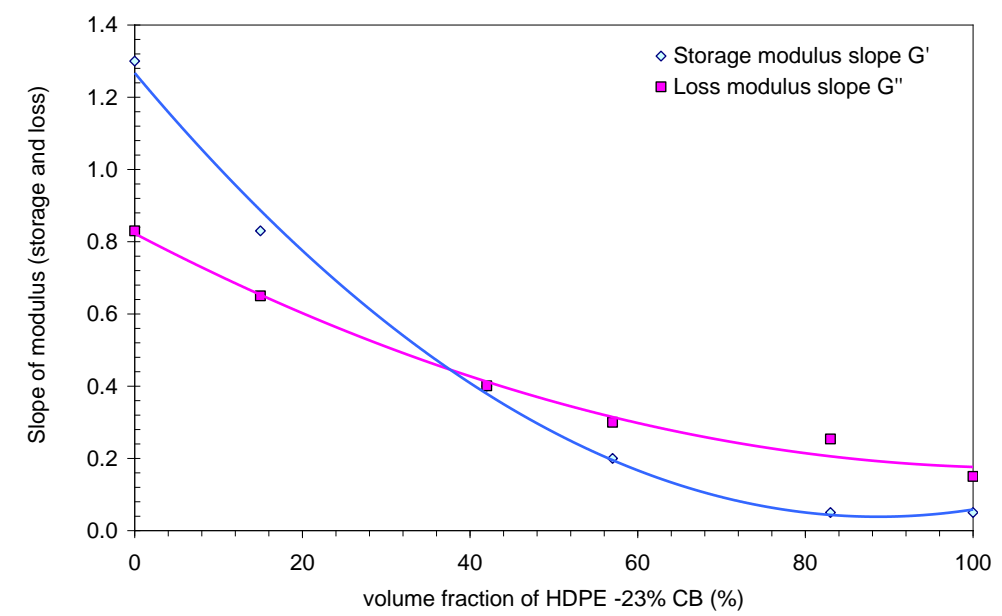

Fig. 14. Change of the modulus slope as a function of hdPE-23\%NCB quantity at $280{ }^{\circ} \mathrm{C}$.

-Phases co-continuity prediction

The sPS phase must remain the majority to provide a good thermal conductivity in the biphasic CPC. This is why we are looking for the beginning of the hdPE phase continuity, i.e. the minimum content to obtain satisfactory electrical conductivity through the material.

Tab. 7 summarizes the different results from the rheological properties (strain sweep, viscosity, slope G' and G') measurements. The percolation value from these rheological measurements show the co-continuous phase situated between 20 and $40 \%$. 
Tab. 7. Measured values of co-continuity region.

\begin{tabular}{ccc}
\hline Reference & $\begin{array}{c}\text { Phase percolation - } \\
\text { hdPE-NCB }\left(\phi_{1}\right)\end{array}$ & $\begin{array}{c}\text { Phase percolation - } \\
\text { sPS }\left(\phi_{2}\right)\end{array}$ \\
\hline Fig. 9 & $\# 40 \%$ & $\left(1-\phi_{1}\right)$ \\
Fig. 10 & $40 \%$ & $\left(1-\phi_{1}\right)$ \\
Fig. 11 & $20-40 \%$ & $\left(1-\phi_{1}\right)$ \\
& $38 \%$ & $\left(1-\phi_{1}\right)$ \\
Fig. 14 & & \\
\hline
\end{tabular}

\section{Conclusions}

The purpose of this paper is to obtain the boundary of the co-continuous region of the biphasic CPC based on high density poly(ethylene) filled with carbon black blended with syndiotactic poly(styrene). This biphasic CPC is aimed to conduct both the heat and electricity through its two different phases.

In the first step, we separately studied rheological properties of the electrical and the thermal conductive phases. The effect of carbon black on the hdPE viscosity shows a strong reinforcement of the matrix due to particles associated in very well structured aggregates. The dielectric ceramic micro filler (boron nitride) strongly increases the viscosity of SPS although this phase exhibits a very fluid and strong Newtonian behavior.

The co-continuous region is studied by means of rheological measurements. The elastic modulus (with viscous modulus) was found to be the most sensitive rheological property to accurately detect the co-continuous morphology in our system. It was found to be at $40 \% \mathrm{v} / \mathrm{v}$ of hdPE-NCB, which can be interpreted as the phase inversion.

\section{Materials and methods}

\section{Materials}

The electrically conductive phase was high density polyethylene provided by ATOFINA (Finathene 5203). The adjusted carbon black (NCB) content was obtained by blending with a master batch filled with $23 \% \mathrm{v} / \mathrm{v}$ of NCB (Vulcan XC $72-\mathrm{N} 472$ from Cabot) made by PREMIX (PRE-ELEC TP 5813).

Tab. 8. Main characteristics of polymers.

\begin{tabular}{cccc}
\hline Properties & hdPE & hdPE-NCB & sPS \\
\hline Producer & Ato-Fina & Premix & Dow \\
Trade name & Finathene 5203 & PRE-ELEC TP 5813 & QA101 Questra \\
$\mathrm{T}_{\mathrm{g}}\left({ }^{\circ} \mathrm{C}\right)$ & -30 & - & 99 \\
$\mathrm{~T}_{\mathrm{m}}\left({ }^{\circ} \mathrm{C}\right)$ & 133 & $133.6 \pm 0,5$ & 275 \\
$\mathrm{~T}_{\mathrm{c}, \mathrm{n}}\left({ }^{\circ} \mathrm{C}\right)$ & 107 & $111.5 \pm 0,5$ & - \\
$\Delta \mathrm{H}_{\mathrm{m}} / \Delta \mathrm{H}_{\infty}\left(\mathrm{J} . \mathrm{g}^{-1}\right)$ & $95 / 303$ & $95 / 303$ & $28.9 / 53.2$ \\
$\mathrm{X} \%$ cristallinity & 31 & 31 & 51 \\
Density $\left(\mathrm{g} . \mathrm{cm}^{-3}\right.$ à $\left.25^{\circ} \mathrm{C}\right)$ & 0.95 & $0.93 \pm 0,05$ & 1.05 \\
$\%$ carbon black $\mathrm{v} / \mathrm{v}$ & & 23 & \\
$\%$ carbon black w/w & & 35 & \\
\hline
\end{tabular}


Tab. 9. Fillers properties ( ${ }^{\star}$ from producer).

\begin{tabular}{lcc}
\hline Filler & boron nitride & Vulcan XC72 \\
\hline Chemical formula & $\mathrm{BN}$ & $\mathrm{NCB}$ \\
Density $\mathrm{d}\left(\mathrm{g} \cdot \mathrm{cm}^{-3}\right)^{*}$ & 2.30 & 1.8 \\
Melting temperature $\mathrm{T}_{\mathrm{m}}\left({ }^{\circ} \mathrm{C}\right)^{*}$ & 3027 & \\
Thermal conductivity $\mathrm{k}\left(\mathrm{W} \cdot \mathrm{m}^{-1} \cdot \mathrm{K}^{-1}\right)$ at $300 \mathrm{~K}^{*}$ & 125 & $6-175[34]$ \\
Specific heat $\mathrm{C}_{\mathrm{p}}\left(\mathrm{J} . \mathrm{kg}^{-1} \cdot \mathrm{K}^{-1}\right)$ at $300 \mathrm{~K}^{*}$ & 730 & - \\
Electrical resistivity $\rho(\Omega \cdot \mathrm{cm})$ at $300 \mathrm{~K}^{*}$ & $2.10^{14}$ & - \\
lodine number $(\mathrm{mg} / \mathrm{g})$ & - & 254 \\
Absorption DBP $(\mathrm{ml} / 100 \mathrm{~g})$ & & 174 \\
Particle diameter $(\mu \mathrm{m})$ & 8 & $3010^{-3}$ \\
Shape factor $[22]$ & $79[22]$ & - \\
\hline
\end{tabular}

The thermally conductive phase was QUESTRA syndiotactic polystyrene from DOW CHEMICAL (U.S.A.). Main properties of polymers are presented in Table 8.

Thermally conductive fillers dispersed in the SPS matrix: BN [25] was provided by MCSE (France). Some of the filler characteristics are summarized in Tab. 9.

\section{Experimental Techniques}

Each component was dried during $12 \mathrm{~h}$ under vacuum at $90{ }^{\circ} \mathrm{C}$ before blending. The blending process preceded in three stages:

The electrically conducting phase was made by hdPE blending with master batch hdPE-23\%NCB in a twin screws extruder contra-rotating BRABENDER at 20 or $30 \mathrm{rpm}$. The temperature profile from feed to die was $190 / 195 / 205^{\circ} \mathrm{C}$.

Processing of thermally conducting phase was obtained by mixing of sPS pellets with ceramic fillers in a single-screw extruder, FAIREX. The mixing speed was $30 \mathrm{rpm}$ and the temperature profile from the feed to die was $275 / 277 / 280 / 280{ }^{\circ} \mathrm{C}$.

Elaboration of biphasic CPC was made by blending electrical phase with thermal phase in the twin-screw extruder contra-rotating, BRABENDER. Compounds were blended at $275 / 280 / 280{ }^{\circ} \mathrm{C}$ with a mixing speed of $20 \mathrm{rpm}$. The die was a split of 5 $x 50 \mathrm{~mm}$ to obtain tapes. No anisotropy was expected to be generated during this process.

Thermo Gravimetric Analysis was used to check the filler content by using a SETARAM TGA. Samples weight was approximately $30 \mathrm{mg}$ and the precision of measurements was estimated to be less than $0.5 \%$.

For volume fraction conversion, density measurements were carried out with a pycnometer at room temperature $\left(27^{\circ} \mathrm{C}\right)$ in methanol.

Rheological properties were performed with a rotational rheometer BOHLIN Gemini 200. The measuring system was parallel plates ETC PP of $25 \mathrm{~mm}$ diameter. The melt oven was set at a temperature of $280{ }^{\circ} \mathrm{C}$, corresponding to the processing conditions. In the first step, the change of viscosity as the shear rate rises was studied by the use of various models: Cross, Carreau and power law [35]. Then, an amplitude sweep is carried out between 0.1 and $10 \%$ of strain to determine the linear region. This allowed a frequency sweep (between $10^{-3}$ and $100 \mathrm{~Hz}$ ) to study the change of complex modulus and viscosity. 
To characterize the rheological behavior of ours systems, our approach was to describe the flow curves of monophasic and biphasic systems by power law equations, Cross and Carreau models and use of a superposition principle to account for the system characteristics.

The power law is given by Eq. 3:

$\eta=K \dot{\gamma}^{(n-1)}$

where " $\mathrm{n}$ " is the flow behavior index and " $\mathrm{K}$ " is the flow consistency index.

For a large range of shear rate, the viscosity follows two Newtonian limits (at low and high shear rates). These different behaviors can be taken into consideration by the following models. The Cross model is presented by Eq. 4:

$\eta=\frac{\eta_{0}-\eta_{\infty}}{\left(1+\frac{\dot{\gamma}}{\dot{\gamma}_{c}}\right)^{(1-n)}}$

where " $\eta_{0}$ " and " $\eta_{\infty}$ " represent respectively the Newtonian limit at zero and infinite shear rates. The parameter $\dot{\gamma}_{c}$ is the critical shear rate above which the viscosity follows a transition between Newtonian and shear thinning behavior.

The Carreau-Yasuda model allows fitting the transition at the critical shear rate by the use of the parameter "a" [cf. Eq. 5]:

$$
\eta=\eta_{\infty}+\frac{\eta_{0}-\eta_{\infty}}{\left[1+\left(\frac{\dot{\gamma}}{\dot{\gamma}_{c}}\right)^{a}\right]\left(\frac{1-n}{a}\right)}
$$

This model is the most flexible since it is corresponding to Cross model when " $a=1$ " and to the former Cross model for " $a=2$ ".

For a constant shear rate, the interactions between fillers and macromolecules can be determined by the use of Maron \& Pierce model [29]. This model has been successfully tested on systems with carbon black [26]. It is presented by Eq. 6:

$$
\frac{\eta_{e f f}}{\eta_{m}}=\frac{1}{\left[1-\frac{\phi}{\phi_{m}}\right]^{2}}
$$

where $\phi_{m}$ represents, for a given shear rate, the maximum volume fraction over which the interactions between fillers and matrix are no more optimum.

Dean-Mo [30] proposed a model for ceramics at high filler content and sufficiently high shear stress (Eq. 7):

$$
\frac{\eta}{\eta_{m}}=\left[a\left(\phi_{m}-\phi\right)\right]^{-2}
$$

where the parameter " $a$ » is the slope of the straight line $" 1-\eta_{0}^{-1 / 2}=f(\phi) »$. The straight line « $y=a x+b$ » allows to determine « $\phi_{m}$ » from Eq. poniżej: 
$\phi_{m}=\frac{1-b}{a}$

The storage modulus G' and loss modulus G" are sensitive parameters to the structure of melt. It is possible to make out cooperative behavior, i.e. if interactions are strong or not. For instance, we can follow the gelation of starch macromolecules with the temperature effect and acid reactant because the system goes from suspension behavior to the one of gel [36]. In the case of polymer blends, in some conditions the co-continuity region can be determined [37].

\section{Acknowledgements}

The authors would like to thank, H. Bellégou, H. Guézénoc, F. Perresse for their contribution to this work and the French Ministry of Research \& Technology for financial support.

\section{References}

[1] Huang, J-C. Adv. Polym. Tech. 2002, 21, 299.

[2] Xue, Q. Eur. Polym. J. 2004, 40, 323.

[3] Chung, D. D. L. Smart Materials \& Structures, 2004, 13, 562.

[4] Wang, X.; Chung, D. D. L. Sensors \& Actuators, A: Physical, 1998, 71, 208.

[5] Bartlett, P.N.; Archer, P. B. M.; Ling-Chung, S. K. Sensor. Actua., 1989, 19, 125.

[6] Feller, J. F. ; Chauvelon, P. ; Linossier, I. ; Glouannec, P. Polym. Test. 2003, 22, 831.

[7] El-Tantawy, F.; Kamada, K.; Ohnabe, H. Mater. Lett. 2002, 56, 112.

[8] Chiu, H.-T. ; Chiu, W.-M. J. Appl. Polym. Sci., 1996, 61, 607.

[9] Abdel-Bary, E. M.; Amin, M.; Hassan, H. H. J. Polym. Sci. Pol. Chem. 1977, 15, 197.

[10] Zee, F.; Judy, J. W. Sensor. Actua. B: Chem., 2001, 72, 120.

[11] Gubbels, F.; Blacher, S.; Vanlathem, E.; Jerome, R.; Deltour, R.; Brouers, F.; Teyssie, P. Macromolecules, 1995, 28, 1559.

[12] Willemse, R. C.; Posthuma de Boer, A.; van Dam, J.; Gotsis, A. D. 1998, 39, 5879.

[13] Lux, F. J. Mat. Sci., 1993, 28, 258.

[14] Cheah, K.; Simon, G.P.; Forsyth, M. Polym. Int., 2001, 50, 27.

[15] Feller, J. F.; Petitjean, E. Macromol. Symp., 2003, 203, 309.

[16] Bloor, D.; Donnelly, K.; Hands, P. J.; Laughlin P.; Lussey, D. J. Phys. D: Appl. Phys. 2005, 38, 2851.

[17] Feller, J. F.; Bruzaud, S.; Grohens, Y. Mater. Lett., 2004, 58, 739.

[18] Feller, J. F.; Linossier, I.; Levesque, G. Polym. Adv. Tech., 2002, 13, 714.

[19] Gubbels, F.; Jérôme, R.; Vanlathem, E.; Deltour, R.; Blacher, S.; Brouers, F. Chem. Mater., 1998, 10, 1227.

[20] Foulger, S.H. J. Polym. Sci. Part B: Polym. Phys., 1999, 37, 1899.

[21] Droval, G.; Glouannec P.; Feller, J. F.; Salagnac P. J. Thermophys. Heat Tr. 2005, 19, 375.

[22] Droval, G.; Feller, J.-F.; Salagnac, P.; Glouannec, P. Polym. Adv. Tech., 2006, $17,732$.

[23] Feller, J. F. J. Appl. Polym. Sci., 2004, 91, 2151.

[24] Droval G.; Glouannec P.; Salagnac P.; Feller, J-F. J. Thermophys. Heat Tr., DOI: 10.2514/1.36193 in press 2008. 
[25] Droval G.; Feller J-F.; Salagnac P.; Glouannec P. Smart Mater. Struct., 2008, 17, 25011.

[26] Feller, J.-F.; Linossier, I. Macromol. Symp., 2003, 203, 317.

[27] Rodriguez, F.; Cohen, C. Principles of polymer systems; Taylor \& Francis, 2003, 282.

[28] Progelhof, R.C.; Throne, J. L.; Ruetsch, R. R. Polym. Eng. Sci., 1976, 16, 615.

[29] Fox, L. P. Carbon black-polymer composites; Sichel, E K. Ed., New-York: Marcel Dekker Inc.; Chapter 6, 1982, 163.

[30] Dean-Mo, L. J. Mater. Sci., 2000, 35, 5503.

[31] Park, C.; Yoon, J.; Thomas, E. L. Polymer, 2003, 44, 6725.

[32] Bueche F. J. Polym. Sci., 1960, 43, 527.

[33] Prochazka, F. ; Dima, R. ; Majesté, J-C. ; Carrot, C. e-Polymer, 2003, 40,1.

[34] Wolff, S.; Wang, M. J. Carbon Black Science \& Technology, 2nd Ed., Vol. 9, Marcel Dekker, New York, 1993:289-355.

[35] Nichetti, D.; Manas-Zloczower, I. J. Rheol., 1998, 42, 951.

[36] Divers, T.; Pillin, I.; Feller, J.-F.; Levesque, G.; Grohens, Y. Starch - Stärke, 2004, 56, 389.

[37] Graebling, D.; Muller, R.; Palierne, J.F. Macromolecules, 1993, 26, 320. 